\title{
Effect of pharmacovigilance training programme on quantitative and qualitative adverse drug reaction reporting
}

\author{
Sangita D. Jogdand ${ }^{1 *}$, Mugdha R. Padhye ${ }^{1}$, Shailesh Nagpure ${ }^{1}$, Raju K. Shinde ${ }^{2}$
}

\author{
${ }^{1}$ Department of Pharmacology, \\ ${ }^{2}$ Department of Surgery, \\ Jawaharlal Nehru Medical \\ College, Sawangi, Meghe, \\ Wardha, Maharashtra, India
}

Received: 16 March 2017

Accepted: 22 April 2017

*Correspondence to:

Dr. Sangita D. Jogdand,

Email: drsangitaraj@gamil.com

Copyright: (C) the author(s), publisher and licensee Medip Academy. This is an openaccess article distributed under the terms of the Creative Commons Attribution NonCommercial License, which permits unrestricted noncommercial use, distribution, and reproduction in any medium, provided the original work is properly cited.

\begin{abstract}
Background: Adverse Drug Reactions(ADRs) are required to monitored in post marketing phase for unstudied ADR or beneficial effect which were not evident in controlled study design, but ADRs are usually under reported due to misbelieves or ignorance of health care worker. There is increasing numbers of adverse drug reaction monitoring centers in India affiliated to governing council but are in primitive phase. Also, there is lack of knowledge and attitude towards necessity for proper reporting of ADR, understanding of terminologies. Hence present study was undertaken to assess out of educational intervention in the form of simulated ADR workshop.

Methods: Hundred nursing staff of JNMC were trained through Simulation Workshop i.e. initial knowledge as assessed before intervention, followed by explanations of every terminology essential for quality reporting of ADR. Ideal ADR reports were provided for study and ADR scenario was given for reporting of ADR. Deficiencies in reported ADR explained to participants. Post intervention knowledge and reporting was assessed. Deficiencies in actual ADR were pursued for three months.

Results: There was statistically significant improvement observed in knowledge ( $\mathrm{p}<0.01$ ) and corresponding, proportionate quality parameters of ADRs as suggested by $\mathrm{Z}$ test.

Conclusions: Educational intervention through simulated ADR and understanding about significance of ADR reporting's and related terminologies improves quality as well as numbers of ADR reporting.
\end{abstract}

Keywords: Adverse drug reaction, Pharmacovigilance, Quality report

\section{INTRODUCTION}

Vast numbers of the drugs are available in markets which are widely prescribed by physician that leads to increased number of adverse drug reactions (ADR). Newer drug molecules are being constantly entering in the market that needs to be monitored for its ADR. Monitoring of ADRs related old as well as newer drug is essential because all the drugs are usually tested in controlled conditions with strict inclusion and exclusion criterion usually in developed western countries that have different genetics and environmental condition than that of Asian countries. In real life situations after marketing, the drug is being prescribed to all indicated patients in all age groups either alone or with other drugs. Drug may be prescribed in pregnancy unless contraindicated. Obscured ADRs or unexpected therapeutic benefits may be discovered in Pharmacovigilance studies. Mortality and high morbidity due to ADR impose substantial financial burden nearly 100 million dollars in US per year. ${ }^{1}$

Periodic evaluation of ADR helps to identify pattern of ADR to improve the safety of the drugs. National and International data helps in revision of labelling of product and patients education program. Banning or withdrawal of the drug after marketing is possible due to ADR monitoring. Ideal Pharmacovigilance program should have Monitoring, Detection, Evaluation, Documentation and reporting of ADRs. ${ }^{2}$

International adverse drug reaction monitoring centre is managed by Uppsala Monitoring Centre at Sweden, 
under WHO. India started ADR monitoring in 1986 with twelve regional centres and became a member of WHO international monitoring centre in 1997 with approved six regional ADR monitoring centres. In 2004, Indian government launched National Pharmacovigilance program of India (PvPI) and converted to Indian Pharmacopoeia Commission (IPC) in 2011. In Pharmacovigilance program of India, ADR are identified and spontaneously reported by health care professionals like physician, dentists, nurses and pharmacists of adverse drug reaction monitoring centres. Predesigned Individual case safety reports (ICSR) consists of patients' information, suspected adverse reaction, suspected medication and identifiable reporter. These ICSR were collected by approved ADR Monitoring Centres (AMCs). Reporting in standard format, follow-up for completeness and uploading to software is a primary responsibility of AMCs. These reports assessed through Vigiflow (web based ICSR management system) of WHO-UMC causality assessment system by National Coordination Centre (NCC) for quality and signal review for improving safety of Indian patients. ${ }^{3}$

Presently there are 150 AMC working in four zones i.e. East, West, South and North across the country and number being continuously increasing; plying a vital role in collecting ADRs. Some of the AMC are responsible for training and technical support at regional level. Except few AMC in India, ADR vigilance is in primitive stage which leads to under reporting of ADR. ${ }^{4}$

Our Jawaharlal Nehru Medical College is newly recognised ADR-AMC reporting centre in July 2016 and it was observed that there is lack of awareness about ADR monitoring and ideal reporting of ADR in the health care workers; hence study was undertaken to assess the impact of Pharmacovigilance training program on ADR reporting in terms of quality and quantity of ADR.

Aim of the study was to study and compare the effect of Pharmacovigilance training programme on ADR reporting at AVBR hospital.

\section{Objectives}

- To study and compare number of ADR reporting before and after Pharmacovigilance training program.

- To compare quality of ADR reporting before and after Pharmacovigilance training program.

\section{METHODS}

Three hour training workshop was conducted for the nursing staff at AVBRH on $30^{\text {th }}$ of June 2016. A pre test was conducted in questionnaire format for assessment of knowledge about Pharmacovigilance program of India before starting the training. The training session included sensitization on basic terminologies used in Pharmacovigilance i.e. adverse drug reaction, suspect drug, adverse event, concomitant conditions, concomitant medications, causal relationship, serious/non-serious cases, criteria for seriousness, re-challenge and dechallenge. All the participants were sensitized about causes of non reporting, importance of ADR reporting and method of ADR reporting as aimed by Pharmacovigilance program of India (PvPI). Quality ADR reporting was explained and ideal ADR reports were circulated amongst them for study. Blank ADR forms were given to them with case scenario for ideal reporting of ADR. Assessment of quality ADR reporting was done by expert from AMC of JNMC; lacunas in ADR reporting were explained to them. Effect of training was assessed by post test questionnaire. Pre-training ADR reports of three months (April, May and June) were compared with post training ADR reports of three months (July, August, September) for quantity as well as quality of the reports.

Case reports which were considered valid for quantitative analysis:

- An identifiable patient

- A suspect drug

- An adverse event

- an identifiable reporter

The parameters for assessing the quality of a cases: ${ }^{5}$

- Event and drug coding using MeDRA (Medical Dictionary for Regulatory Activities)

- Concomitant medications and concomitant conditions

- Relevant medical history

- Causality assessment

- Seriousness criteria

\section{RESULTS}

Pre test mean score $(2.36 \mathrm{SD} \pm 0.75)$ and post test mean score $(6.46 \mathrm{SD} \pm 1.24)$ there was nearly threefold increase in the knowledge after training phase, in all participants showing significant statistical difference as suggested by $\mathrm{p}$ value less than 0.001 .

Table 1: Pre and post test score of knowledge of participants.

\begin{tabular}{|c|c|c|c|c|c|}
\hline \multirow{3}{*}{$\begin{array}{l}\text { Three } \\
\text { hour } \\
\text { training } \\
\text { ADR } \\
\text { reporting }\end{array}$} & & Mean & SD & $\begin{array}{l}\text { Std. } \\
\text { error }\end{array}$ & $\begin{array}{l}P \\
\text { value }\end{array}$ \\
\hline & $\begin{array}{l}\text { Pre test } \\
\text { score }\end{array}$ & 2.36 & 0.75 & 0.12 & \multirow{2}{*}{0.001} \\
\hline & $\begin{array}{l}\text { Post test } \\
\text { score }\end{array}$ & 6.46 & 1.24 & 0.22 & \\
\hline
\end{tabular}

In pre-intervention quarter (April - June) only 48 ADR reporting were received out of which only $16(33.33 \%)$ were matched to expected level of quality (April- 36\%, May-40\% and June-27.27\%). Reporting of quality was at random. 
Table 2: Three months pre-intervention data of ADR reporting.

\begin{tabular}{|lll|}
\hline Month & Quantity & Quality \\
\hline April & 11 & $04(36.36 \%)$ \\
\hline May & 15 & $06(40 \%)$ \\
\hline June & 22 & $06(27.27 \%)$ \\
\hline Total & 48 & $16(33.33 \%)$ \\
\hline
\end{tabular}

In post intervention quarter (July-September), reporting of ADR was nearly doubled i.e. 96 ADR reports were received as compared to 48 with steady improvement in the quality of reporting i.e. $80 \%$ in July $92.59 \%$ in August and $95.45 \%$ in September with overall improvement to $90.62 \%$.

$\mathrm{Z}$ test was applied for difference between proportions (of positive responses from the group) at $0.05 \%$ level of significance and $\mathrm{p}$ value was calculated. The difference between proportions was significant for all the parameters. After intervention, there was statistically significant improvement in quality of all parameters like event and drug coding, concomitant conditions and medications, relevant medical history, seriousness criteria and causality assessment as shown by $\mathrm{p}$ value which is less than 0.05 .

Table 3: Three months post-intervention data of ADR reporting.

\begin{tabular}{|lll|}
\hline Month & Quantity & Quality \\
\hline July & 25 & $20(80 \%)$ \\
\hline August & 27 & $25(92.59 \%)$ \\
\hline September & 44 & $42(95.45 \%)$ \\
\hline Total & 96 & $87(90.62 \%)$ \\
\hline
\end{tabular}

Table 4: Comparison of quality parameters pre and post intervention.

\begin{tabular}{|c|c|c|c|c|c|c|c|c|}
\hline \multirow{2}{*}{ Quality Parameters } & \multicolumn{3}{|c|}{ Pre intervention $(\mathrm{n}=48)$} & \multicolumn{3}{|c|}{$\begin{array}{l}\text { Post intervention } \\
(\mathrm{n}=96)\end{array}$} & \multirow{2}{*}{$\mathbf{Z}$ score } & \multirow{2}{*}{ p-value } \\
\hline & Yes & No & $\%$ & Yes & No & $\%$ & & \\
\hline Event and drug coding & 44 & 4 & $91.6 \%$ & 96 & 00 & $100 \%$ & -2.8685 & 0.004 \\
\hline Concomitant conditions and medications & 21 & 27 & $43.7 \%$ & 84 & 12 & $87.5 \%$ & -5.5691 & 0.000 \\
\hline Relevant medical history & 25 & 23 & $52 \%$ & 84 & 12 & $87.5 \%$ & -4.6709 & 0.000 \\
\hline Seriousness criteria & 37 & 11 & $77 \%$ & 94 & 02 & $97.9 \%$ & -4.1123 & 0.000 \\
\hline Causality assessment & 20 & 28 & $41.6 \%$ & 86 & 10 & $89.6 \%$ & -6.1501 & 0.000 \\
\hline
\end{tabular}

\section{DISCUSSION}

There are various challenges in our country about ADR reporting as very less data is available about ADRs of traditional, herbal medicine and its interaction with various drugs to be monitored for ADR. There is lack of attitude of local manufacturer towards investing money for ADR monitoring of generic drugs. Adverse Drugs reactions may be categorized depending on frequency as very common (>10\%), Common $(>1 \%$ and $<10 \%)$, Uncommon $(>0.1 \%$ and $<1 \%)$, Rare $(>0.01$ and $<0.1 \%$ ) and very rare if $<0.01$ which is called an optional categories.

Pharmacovigilance is the pharmacological science relating to the collection, detection, assessment, monitoring, and prevention of adverse effects related pharmaceutical products for safety of patients and reducing the economical burden, which largely focuses on adverse drug reactions (ADRs). An ADR is defined by WHO as "Any response to a drug which is noxious and unintended, and which occurs at doses normally used in man for the prophylaxis, diagnosis or therapy of disease, or for the modification of physiological function." It also includes adverse drug reactions resulting from medication errors like overdose, misuse and abuse of the medicinal product. ${ }^{6,7}$

Present study projects that there was very limited knowledge about the ADR reporting as expected to governing council for ADR monitoring which was reflected through pre-test assessment. There was significant $(\mathrm{p}<0.001)$ improvement in knowledge of participants after sensitization workshop depicted by post test. It was observed that lack of understanding regarding pharmacovigilance was the major cause of under reporting.

Health professionals were unable to decide which drug among the list of medications is responsible for the adverse event. Lack of understanding about ADR reporting leads invalid reporting of the ADR that do not contribute to expected level of signal generation for safety of the patients. Explaining them regarding meaning of suspect medication, concomitant medications and other unfamiliar terms proved to be helpful. This was evident from the increase in reporting rate as well as improved quality ADR report. Lopez - Gonzalez E1 et al observed that ignorance (95\%), lethargy, (77\%), diffidence meaning thereby fear of reporting merely 
suspected ADR (72\%), belief that single reporting may not contribute to medical knowledge- indifference and insecurity about correlating ADR to a drug (67\%) and misbelieve that only safe drugs are marketed $(47 \%)$ are the factors responsible to under reporting of ADR. ${ }^{8}$

In our study, there was significant proportionate improvement in corresponding parameters i.e. event and drug coding, concomitant conditions and medication, relevant medical history, seriousness criteria and causality assessment. There was statistical significant improvement as shown by $\mathrm{p}<0.001$ and $\mathrm{Z}$ test at significance level of $95 \%$ confidence interval (CI). Due to proper sensitization, training workshop and pursuance of quality reporting in post intervention quarter, there was steady improvement in the number of valid ADR ICSR and quality reporting of ADR. All the factors considered in methodology for valid case reports were compiled by the entire participant i.e. 100 nursing staff at AVBR Hospital, Sawangi (Meghe), Wardha, Maharashtra. Our study matches with many of other individual studies, where progressive improvement in the quality of ADR reporting in participants was observed in various health professionals like physicians, dentists, nurses and pharmacists after educational intervention in any form to sensitize about ADR reporting. ${ }^{9-13}$

It also correlates with cluster randomized controlled trial in 1388 physicians conducted by Adolfo Figueiras et al and pharmacists consisting of intervention group of 342 and control group of 1091 by Herdeiro MT et al in the form of one hour educational outreach visit, that emphasis the fact that under reporting of ADR mostly due to personal reasons and there was progressive improvement in first four months and steady reporting in limited subsequent period, and there after decreasing trends in reporting of ADR were observed. ${ }^{14,15}$

\section{Limitations}

Short term assessment of effect on ADR reporting of healthcare providers were assessed which needs to be evaluated with long term longitudinal studies.

\section{CONCLUSION}

Educational intervention in the form which will bridge the gap of knowledge that lacking for reporting of the ADR and sensitization for the need of reporting the ADR will definitely increase quantity and quality of ADR reporting. As council is planning to increase AMC centers, hence such intervention to sensitize health care workers is essential. As there is decreasing trends is observed by other researcher periodic re-sensitization may also be helpful for continues high quality and adequate numbers of ADR reporting.

Funding: No funding sources Conflict of interest: None declared
Ethical approval: The study was approved by the Institutional Ethics Committee

\section{REFERENCES}

1. Dhikav V, Singh S, Anand KS. Adverse drug reaction monitoring in India. J Indian Acad Clin Med. 2004;5(1):27-33.

2. Allu PH, Nambari H, Majjaru C. Adverse drug reaction monitoring and reporting at H.S.K Hospital and Research Center Bagalkot. Research and Reviews: Journal of Hospital and Clinical Pharmacy. 2016;2(2):54-62.

3. Lihite RJ, Lahkar M. An update on the Pharmacovigilance programme of India. Front Pharmacol. 2015;6:194.

4. Pharmacovigilance program of India (PvPI) National coordination centre, Indian Pharmacopoeia commission Ghaziabad. Available from: http://www.ipc.gov.in/PvPI1/pv_amcs.html

5. European medicines agency. Guideline for good clinical practice. Available from: http://www.emea.eu.int/pdfs/human/ich/013595en.pd f. Accessed January20, 2006.

6. Yadav S. Status of adverse drug reaction monitoring and pharmacovigilance in selected countries. Indian J Pharmacol. 2008;40(1):S4-9.

7. Introduction- Indian Pharmacopoeia commission. Available from: http://ipc.nic.in/writereaddata/linkimages/introductio n\%20to\%20pv-4112657251.pdf

8. Lopez-Gonzalez E, Herdeiro MT, Figueiras A. Determinants of under-reporting of adverse drug reactions: a systematic review. Drug Saf. 2009;32(1):19-31.

9. Nazario M, Feliu JF, Rivera GC. Adverse drug reactions: The San Juan Department of Veterans Affairs Medical Centre experience. Hosp Pharma. 1994;244-6:249-50.

10. Scott HD, Thacher-Renshaw A, Rosenbaum SE, Waters WJ, Green M, Andrews LG, et al. Physician reporting of adverse drug reactions: results of the Rhode Island adverse drug reaction reporting project. Jama. 1990 Apr 4;263(13):1785-8.

11. Fincham J. A statewide program to simulate reporting of adverse drug reactions. J Pharm Pract. 1989;2:239-44.

12. McGettigan P, Golden J, Conroy RM, Arthur N. reporting of adverse drug reactions by hospital doctors and response to intervention. $\mathrm{Br} \mathrm{J}$ Clin Pharmacol. 1997;44:98-100.

13. Hanafi S, Torkamandi H, Hayatshahi A, Gholami K. An educational intervention to improve nurses' knowledge, attitude, and practice towards reporting of adverse drug reactions. Iran J Nurs Midwifery res. 2014;19(1):101-6.

14. Fugueiras A, Herdeiro MT, Polonia J, Gestal-Otero JJ. An educational intervention to improve physician reporting of adverse drug reactions: A cluster- 
randomized controlled trial. JAMA 2006;296(9):1086-93.

15. Herdeiro MT, Polonia J, Gestal-Otero JJ, Figueiras A. Improving the reporting of adverse drug reaction: a cluster randomized trial among pharmacists in Portugal. Drug Saf. 2008;31(4):335-44.
Cite this article as: Jogdand SD, Padhye MR, Nagpure S, Shinde RK. Effect of pharmacovigilance training programme on quantitative and qualitative adverse drug reaction reporting. Int $\mathbf{J}$ Basic Clin Pharmacol 2017;6:1367-71. 